\title{
Internal flow and air core dynamics in Simplex and Spill-return pressure-swirl atomizers
}

\author{
Milan Malý¹, Lada Janáčková1, Jan Jedelský1, Jaroslav Sláma², Marcel Sapík¹, \\ Graham Wigley ${ }^{3}$ \\ ${ }^{1}$ Faculty of Mechanical Engineering, Brno University of Technology, Czech Republic \\ 2 Provyko s.r.o, Czech Republic \\ ${ }^{3}$ Loughborough University, United Kingdom \\ *Corresponding author: milan.maly@vutbr.cz
}

\begin{abstract}
It is well known that the spray characteristics of pressure-swirl atomizers are strongly linked to the internal flow and that an unstable air core may cause instabilities in the spray. In this paper, a 10:1 scale transparent Plexiglas (PMMA) model of a pressure-swirl atomizer as used in a small gas turbine is introduced. The internal flow was examined using high-speed imaging, laser-Doppler anemometry and computational fluid dynamics tools. The experimental and numerical results were analysed and compared in terms of the air core morphology and its temporal stability. Two different liquids were used, Kerosene-type Jet A-1 represented a commonly used fuel while p-Cymene (4-Isopropyltoluene) matched the refractive index of the Plexiglas atomizer body. The internal flow characteristics were set using dimensionless numbers i.e. the Reynolds number and Froude number. The flow test conditions were limited to inlet Reynolds numbers from 750 to 1750. Two atomizers were examined to represent a Simplex and Spill-return (SR) geometries. In a comparative manner, the SR atomizer features a central passage in the rear wall of the swirl chamber. The main advantage of this concept is that the fuel is always supplied to the swirl chamber at a high pressure therefore providing good atomization over a wide range of the injection flow rate. However, the presence of the spill orifice strongly affects the internal flow even if the spill-line is closed. The air core in the Simplex atomizer was found fully developed and stable. The SR atomizer behaved differently, the air core did not form at all, and the spray was therefore unstable.
\end{abstract}

\section{Keywords}

Internal flow dynamics, Pressure-swirl, transparent nozzle, CFD

\section{Introduction}

Pressure-swirl (PS) atomizers are used in many applications where a large surface area of droplets is needed or a surface must by coated by a liquid e.g. combustion, fire suspension or air conditioning. PS atomizers are easy to manufacture, reliable and provide good atomization quality. They convert the pressure energy of the pumped liquid into kinetic and surface energy of the resulting droplets. The pumped liquid is injected via tangential ports into a swirl chamber, where it gains a swirl motion, under which it leaves the exit orifice as a conical liquid sheet. The centrifugal motion of the swirling liquid creates a low-pressure zone in the centre of the swirl chamber and generate an air core along the centreline. The flow inside the atomizer is rather complex; it is two-phase with secondary flow effects. There is a strong link between internal flow conditions and the resulting spray characteristics, however, not all aspects of the internal flow are well understood.

Before the advent of computational fluid dynamics, a number of authors attempted to describe the internal flow by relatively simple analytical approaches. One of the first was presented by Taylor [1] which focused on an inviscid analysis using Bernoulli's equation and the principle of maximal flow. Taylor derived an equation for the discharge coefficient $\left(C_{D}\right)$ and the spray cone angle (SCA) solely dependent on the atomizer constant $k=2 \cdot A_{p} /\left(\pi \cdot d_{0^{*}} d_{s}\right)$, where $A_{p}$ is the area of the inlet ports, $d_{o}$ and $d_{s}$ are defined in Figure 1. Similar results were found independently by other authors and these works have been compared and reviewed by Chinn [2, 3]. Results obtained by the inviscid theory are not generally in good agreement with experiments. However, findings from the inviscid theory may be used as a base for design improvements.

The experimental correlations for $C_{D}$ were found to be more complex than the inviscid theory predicted. Rizk and Lefebvre [4] derived a semi-empirical correlation, where, beside the constant $k$, the ratio $d_{s} / d_{0}$ has a strong influence. Jones [5] found a weak dependence of $C_{D}$ on the length of the swirl chamber and exit orifice and liquid viscosity. Ballester [6] added a dependence on the inlet pressure. Benjamin [7] followed the work of Jones [5] and found 
inverse trends for the some parameters. Wimmer and Brenn [8] theoretically uncovered a relatively strong effect of the liquid viscosity on $C_{D}$, which was experimentally confirmed later by Maly et al. [9].

The internal flow characteristics, especially the air core stability, were investigated by a few authors. Halder [10] investigated the air core shape in 21 different transparent atomizers at various inlet mass flow rates of water. Two limiting values of Reynolds number $(\mathrm{Re})$ were conducted for the inception of the air core for each atomizer. Below the lower limit, the air core was not formed at all, while above the upper, it was always found stable. He observed that the limiting Re decreases with an increase in $d_{0} / d_{s}$ and a decrease in $A_{p} / d_{s}$. The stable air core had a cylindrical shape, and for large Re values, it was almost constant in diameter. For Re values close to the limiting value the diameter of the air core sharply increased with increasing Re. A similar concept of limiting values of $R e$ was introduced by Lee et al. [11]. In their experimental work, they used a transparent atomizer with diesel and kerosene for a range of inlet pressures and temperatures. They deduced that the air core stability was a function of Re related to the exit orifice, $R_{e}$. It was stable for $R e>3300$, at lower values it became unstable until for $R_{\circ}$ below 2400 , there was no air core at all due to insufficient centrifugal forces and the spray fluctuated strongly. Kim et al. [12] investigated the influence of diameter and length of the swirl chamber on the air core stability. Atomizers with ratios of $h_{s} / d_{s}$ higher than 1.27 demonstrated an unstable air core. The authors [12] described the unstable air core as having a rotating and double helical structure. Moon [13] found a limiting value of the swirl number $S_{0}=0.6$, which ensured a stable air core.

SR atomizers have rarely been studied while the effect of the spill arrangement on the internal flow is not at all clear. The liquid return can be realized by a single axial orifice, by several off-axis orifices or by an annular slot. The simplest designs use a single, axially placed spill orifice but the problems with spray stability were reported [14, 15] especially under operating regimes with a closed spill-line.

\section{Tested atomizers and liquids}

Both Simplex and SR atomizers were tested together with their geometrically identical transparent copies in 10:1 scale. The dimensions of the original atomizer are documented in Figure 1. It was not possible to manufacture and examine such small atomizers in the transparent version, therefore scaled models had to be used. The scaled atomizers have a modular construction (Figure 2, left). The assembly consists of three parts, each made from Plexiglas. The bottom part contains the swirl chamber with the exit orifice, the central one forms the tangential inlet ports, while the top part is a plain wall in the case of simplex atomizer or contains the spill orifice in the case of the SR atomizer. The modular construction allows each part to be replaced by another of a different geometry or shape. The surfaces of each part were ground and polished to achieve the transparency necessary for optical access.

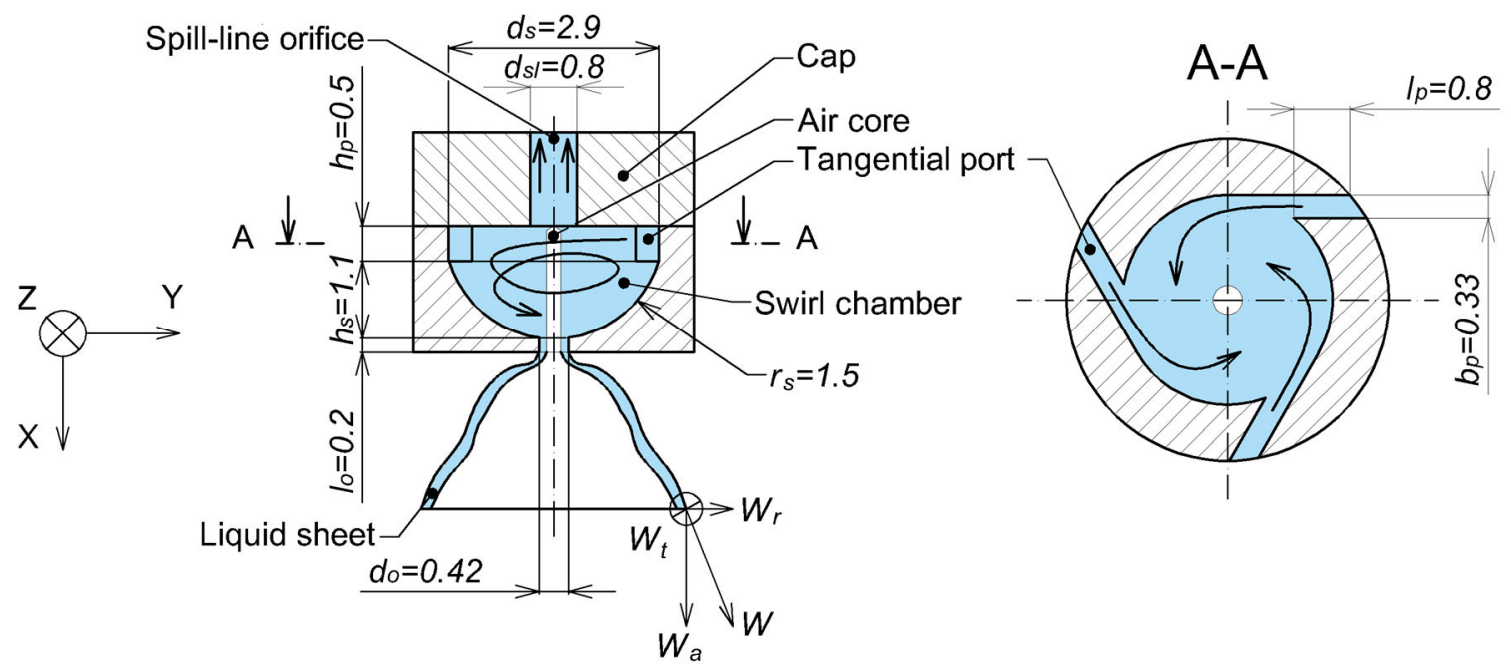

Figure 1. Sketch of the original SR atomizer with the main dimensions in millimetres. The simplex atomizer has no spill-line. The transparent atomizer has all dimensions 10 times larger.

It is necessary to match the flow of the real and scaled atomizers so the relevant dimensionless numbers must be considered. $\mathrm{Re}$ is defined as the ratio of inertial force to the viscous force. In the case of the swirl atomizer, the most common definition of $\mathrm{Re}$ is related to the inlet ports [16] as $R e=w_{p} d_{p} / v$, where $w_{p}$ is mean velocity in the inlet ports, calculated as a volumetric flow rate divided by the total cross-section of inlet ports, $v$ is liquid kinematic viscosity, and $d_{p}$ is the hydraulic diameter of inlet ports $d_{p}=2 h_{p} b_{p} /\left(h_{p}+b_{p}\right)$, see figure 1 . The Re values for 
the scaled model must match those of the original to keep the same internal flow character. So is useful in determining the ratio of the angular momentum to the axial momentum. It can be derived as a function of internal geometry [16]: $S_{0}=\pi R r_{o} / A_{p}$ where $R$ is a radius of flow entry to the swirl chamber. It is evident that the swirl numbers for the real and sized atomizers are identical. The Froude number (Fr) shows the effect of gravity in comparison with the energy of the bulk flow and can be defined as:

$$
F r=\frac{Q}{2 \pi\left(r_{o}^{2}-r_{\text {oac }}^{2}\right) \sqrt{r_{o} g}},
$$

where $Q$ is the volume flow rate and $r_{o a c}$ is the radius of the air core in the exit orifice. To minimize the effect of gravity, it is necessary to keep $\mathrm{Fr}>>1$, as is applicable in the real atomizer case. Spray related dimensionless numbers such as Weber number and Ohnesorge number differ between the real and scaled atomizers by an order of magnitude and thus the spray parameters were not investigated except for the spray cone angle, SCA, close to the exit orifice.

Table 1 lists the experimental regimes with their dimensionless numbers. The operating regimes were derived from those in a previous work [14]. The main control parameter was the inlet pressure of the real atomizer and consequently its mass flow rate, from which the Re was calculated. The SR atomizer was also evaluated with closed spill-line to simulate the maximum injection rate. Two liquids were involved in this analysis with kerosene type Jet A-1 representing the commonly used fuel. However, its refraction index differs from that of the Plexiglas nozzle which complicates the optical measurement inside the transparent atomizer. A liquid with the refraction index very close to the Plexiglas should be used to overcome this problem. For this purpose, several different liquids and mixtures were evaluated to determine the most suitable one. Paracymene (p-cymene or 1-Methyl-4-(propan-2yl)benzene) was chosen. It is a colourless, transparent organic compound with refraction index differing from the Plexiglas by less than 0.001 at $660 \mathrm{~nm}$ wavelength and $25^{\circ} \mathrm{C}$. It also has a relatively low aggressivity to Plexiglas, however, after a few measurement hours it caused cracks in those parts where increased internal stresses may be anticipated, i.e. in the vicinity of bolts and threads. The physical properties of Jet A-1 are $\sigma=0.029 \mathrm{~kg} / \mathrm{s}^{2}$, $\mu_{l}=0.0016 \mathrm{~kg} /(\mathrm{m} \cdot \mathrm{s}), \rho_{l}=795 \mathrm{~kg} / \mathrm{m}^{3}$ and p-cymene: $\sigma=0.028 \mathrm{~kg} / \mathrm{s}^{2}, \mu l=8 \times 10^{-4} \mathrm{~kg} /(\mathrm{m} \cdot \mathrm{s}), \rho_{l}=850 \mathrm{~kg} / \mathrm{m}^{3}$.

Table 1 Operating regimes

\begin{tabular}{|c|c|c|c|c|c|c|c|c|c|}
\hline \multirow{2}{*}{} & \multicolumn{4}{|l|}{ Real atomizer } & \multicolumn{2}{l|}{ Transparent atomizer } \\
\cline { 2 - 10 } & $\mathbf{R e}$ & $\boldsymbol{\Delta} \boldsymbol{p}$ & $\boldsymbol{m}_{\boldsymbol{I}}$ & $\mathbf{F r}$ & $\boldsymbol{C}_{\boldsymbol{D}}$ & $\boldsymbol{m}_{\boldsymbol{I}}$ & $\mathbf{F r}$ & $\boldsymbol{m}_{\boldsymbol{I}}$ & $\mathbf{F r}$ \\
\cline { 2 - 10 } & {$[-]$} & {$[\mathbf{M P a}]$} & {$[\mathbf{k g} / \mathbf{h}]$} & {$[-]$} & {$[-]$} & {$[\mathbf{k g} / \mathbf{h}]$} & {$[-]$} & {$[\mathbf{k g} / \mathbf{h}]$} & {$[-]$} \\
\hline Simplex & 755 & $\mathbf{0 . 5}$ & 5.41 & 137.4 & 0.387 & 54.1 & 6.9 & 29.0 & 3.4 \\
\hline Simplex & 1021 & $\mathbf{1}$ & 7.31 & 293.2 & 0.369 & 73.1 & 9.3 & 39.2 & 4.7 \\
\hline Simplex & 1252 & $\mathbf{1 . 5}$ & 8.97 & 359.8 & 0.365 & 89.7 & 11.4 & 48.1 & 5.7 \\
\hline SR & 1075 & $\mathbf{0 . 5}$ & 7.7 & 308.8 & 0.542 & 77 & 9.8 & 41.3 & 4.9 \\
\hline SR & 1431 & $\mathbf{1}$ & 10.25 & 411.1 & 0.519 & 102.5 & 13.0 & 55.0 & 6.5 \\
\hline SR & 1731 & $\mathbf{1 . 5}$ & 12.4 & 497.3 & 0.510 & 124 & 15.7 & 66.5 & 7.9 \\
\hline
\end{tabular}

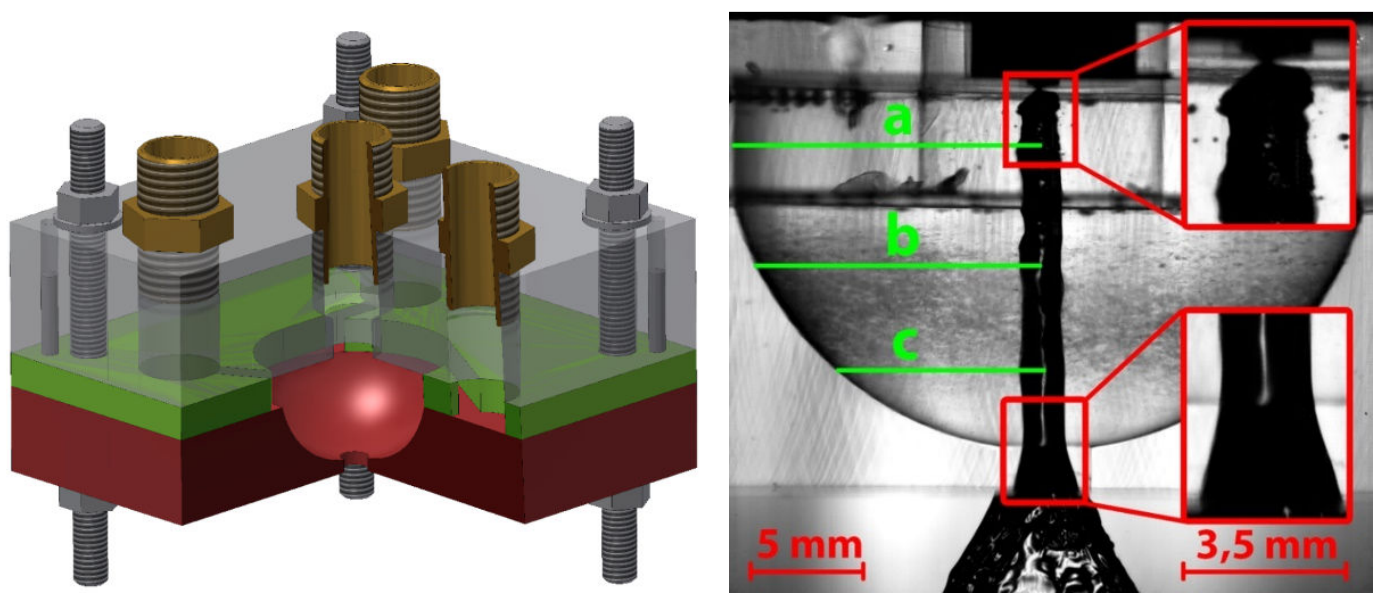

Figure 2. Left: Model of the scaled transparent atomizer. Right: High-speed visualization, p-cymene, $1 \mathrm{MPa}$, simplex. 


\section{Experimental setup}

The experiments were performed on the cold test bench at room temperature. A Photron SA-Z high-speed camera was used to document the spatial and temporal behaviour of the air core. The atomizer was illuminated by a background light using an LED panel. Three records were acquired at each operating regime; a general image showing the whole atomizer while the other two observe the exit orifice and the top of the swirl chamber in close up, see Figure 2 right. The camera frame rate was 20,000 fps for the general image; the resolution was $1024 \times 1024 \mathrm{px}$ and the shutter speed was set to 20 us. The close up records used a frame rate of $28,000 \mathrm{fps}$, resolution $768 \times 904 \mathrm{px}$ and a shutter time of $10 \mu \mathrm{s}$. The air core fluctuations were processed using a Fast Fourier Transform (FFT) applied to the average pixel intensities over rectangle $3 \times 3 \mathrm{px}$.

The laser-Doppler anemometer (LDA), a FlowExplorer (Dantec Dynamics A/S), was employed for the point-wise measurement of the swirl velocity in three cross-sections across the swirl chamber (see Figure 2 right). The axial distances from the top of the swirl chamber were $2.5,8$ and $13 \mathrm{~mm}$ for cross-sections $\mathrm{a}, \mathrm{b}$ and $\mathrm{c}$ respectively. The LDA was configured in the backscatter mode. The measuring volume position, relative to the LDA traverse system has to be corrected due to the different refraction index of the atomizer body and the liquid. Moreover, in the case of kerosene, it was also necessary to correct the measured velocity. The flow tracer particles were SL75 e-spheres with a mean diameter of $45 \mu \mathrm{m}$. The Stokes number, based on the swirl velocity and diameter of the swirl chamber, was less than 0.01 for each regime, which should ensure a sufficiently small flow traceability error.

\section{Numerical setup}

Conservation of mass (continuity) and conservation of momentum (Navier-Stokes) equations were solved numerically using Ansys Fluent 17.2. The flow simulation was conducted as a transient 2D axisymmetric model. A Volume of Fluid (VOF) model with the geo-reconstruct scheme was used to capture the boundary of the air core. The 3D inlet boundary condition was set to conserve the mass flow rate in the radial direction and ensure the same angular momentum in the tangential direction. The pressure outlet boundary condition was applied on the outer boundaries with no-slip conditions applied on the wall boundaries. Laminar flow was assumed due to the low Re values inside the inlet ports, and also due to the fact that inside the swirl chamber, the radial forces of the swirl tend to laminarise the flow [16]. The simulations were performed for both real and scaled atomizers.

The all quad structured mesh with an average skewness 0.058 and average aspect ratio 1.18 was created (Figure 3 ) and the grid independency test was carried out for four different element base sizes in terms of $C_{D}$, SCA and air core diameter $\left(d_{a}\right)$ at the end of the exit orifice $\left(d_{0}\right)$ in a dimensionless form as $d_{a} / d_{0}$ (see Table 2). There was a huge difference between the meshes of 11,684 and 22,669 elements. These differences decreased with further increase in the number of elements, and the mesh with 46,765 elements was chosen as a good compromise between accuracy and calculation speed. Two sizes of the outflow area were also tested, but the difference was found to be negligible.

Table 2. Grid independency test

\begin{tabular}{|c|c|c|c|}
\hline \hline Number of elements & $\boldsymbol{C}_{\boldsymbol{D}}$ & $\boldsymbol{d}_{\boldsymbol{a}} / \boldsymbol{d}_{\boldsymbol{o}}[-]$ & SCA [deg] \\
\hline \hline 11,684 & 0.392 & 0.655 & 58 \\
\hline 22,669 & 0.365 & 0.707 & 58 \\
\hline 46,765 & 0.358 & 0.710 & 57 \\
\hline $68,610^{*}$ & 0.359 & 0.710 & 57 \\
\hline 90,684 & 0.356 & 0.711 & 56 \\
\hline
\end{tabular}

*The base size of elements was the same as in the case of 46,765 element. The outflow area was four times larger.

\section{Results and discussion}

Air core shape

The air core was fully developed in the case of all the Simplex atomizers, as shown in Figure 4. It was cylindrically shaped and larger in diameter inside the exit orifice. Such behaviour has been described by other authors [10, 11, 17]. The dimensionless diameter of the air core in the exit orifice was $d_{a} / d_{o}=0.74 \pm 0.02$ for all the inlet pressures and both liquids with no evident correlations to Re. Inside the swirl chamber $d_{a} / d_{o}=0.47 \pm 0.03$ and was also almost independent of Re. Both findings are in accordance with several authors [10, 18, 19], who reported independent air core size for regimes of high Re. Instabilities, in the form of air core fluctuations, both in the axial and radial direction (Figure 5) were observed at the top of the swirl chamber. These fluctuations are linked with the wavy structure on the air core surface. The frequency of the surface waves $f=32 \pm 4 \mathrm{~Hz}$ was estimated using the FFT analysis of images for the Simplex atomizer with $p$-cymene at $R e=1021$. A similar evaluation was reported by Sumer et al. [20] who used a similarly sized atomizer, but with the velocity in the inlet ports approximately ten times higher they found wave frequencies of $f=273 \mathrm{~Hz}$. 


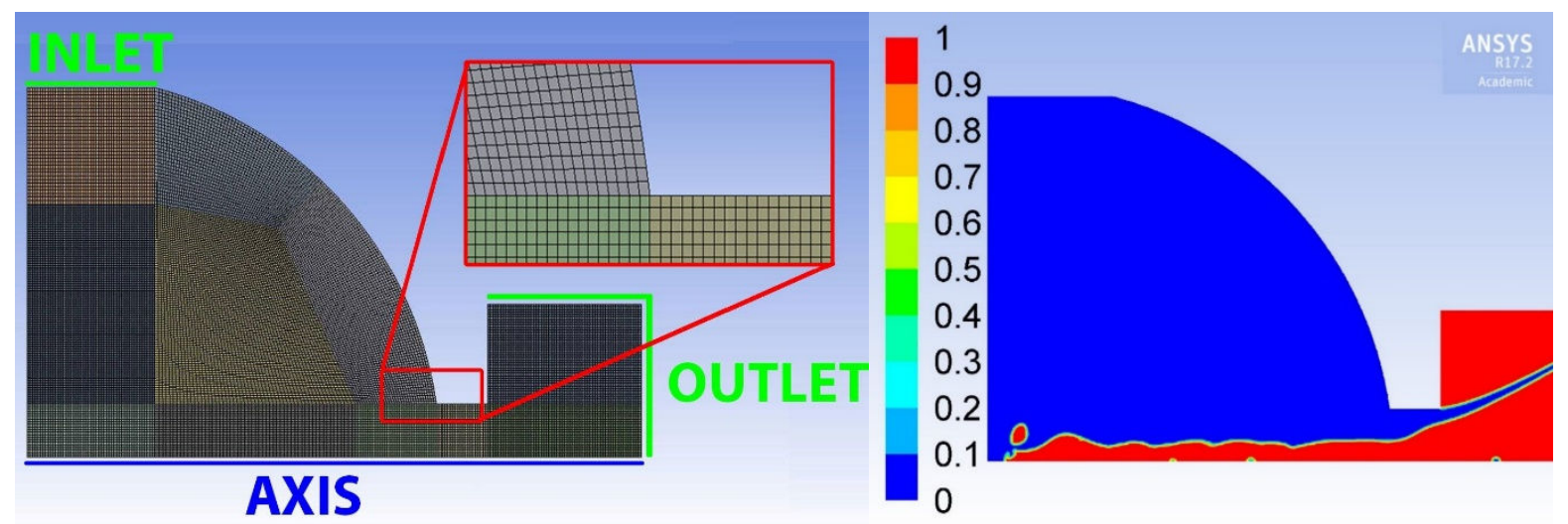

Figure 3. Left: Numerical domain and its mesh. Right: Typical results obtained with the wavy surface of the air core.
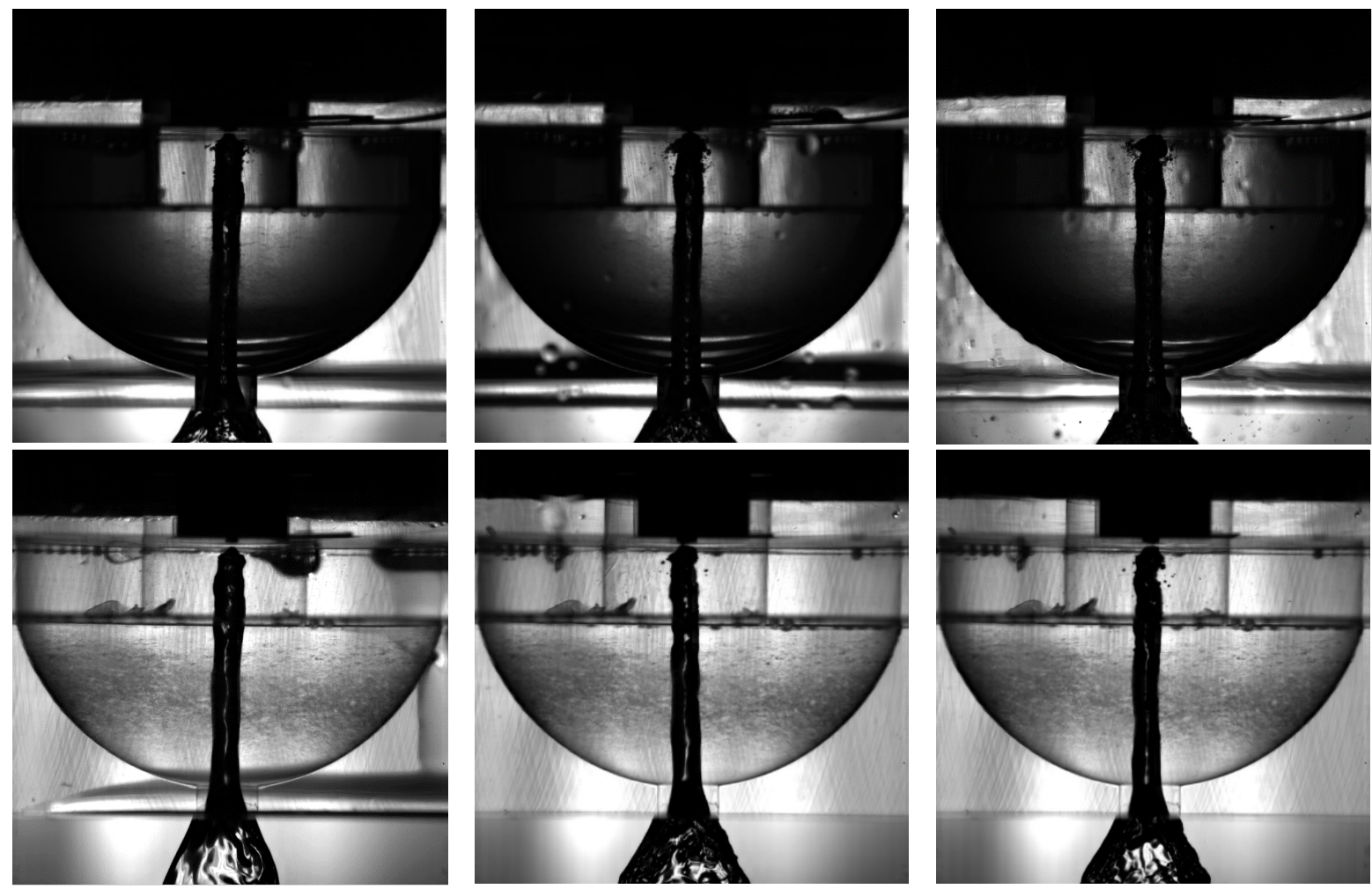

Figure 4. Simplex atomizer, Top: Kerosene, Bottom: $\mathrm{P}$-cymene. From left: equivalent $0.5 \mathrm{MPa}(\mathrm{Re}=755)$, equivalent $1 \mathrm{MPa}$ $(\operatorname{Re}=1021)$, equivalent $1.5 \mathrm{MPa}(\operatorname{Re}=1252)$.
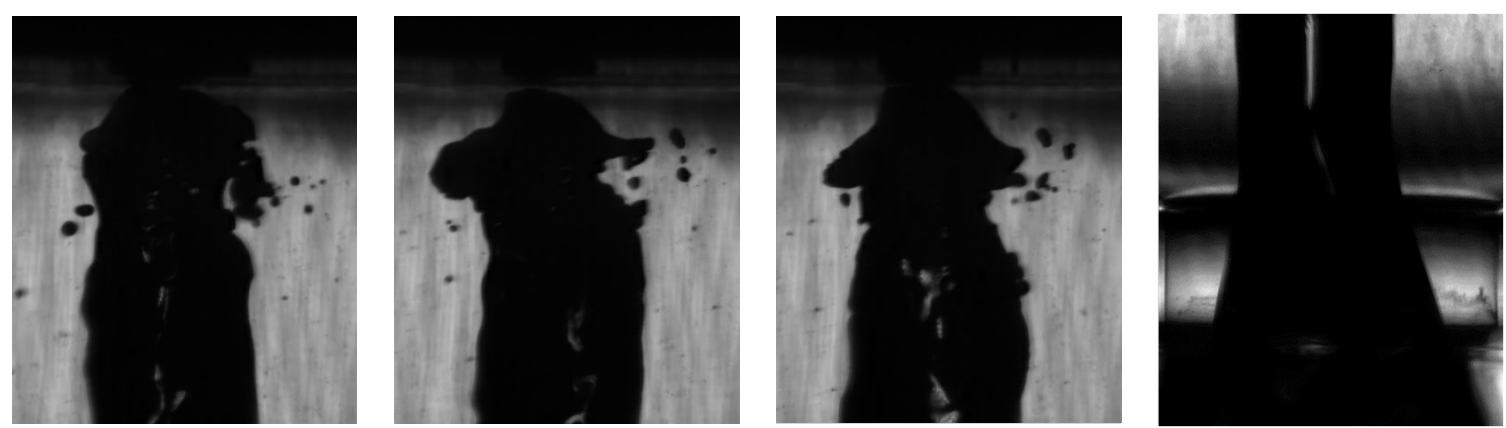

Figure 5. Simplex, p-cymene, $R e=1021$. The detail on fluctuating end of the air core. Right: the detail on the exit orifice. 

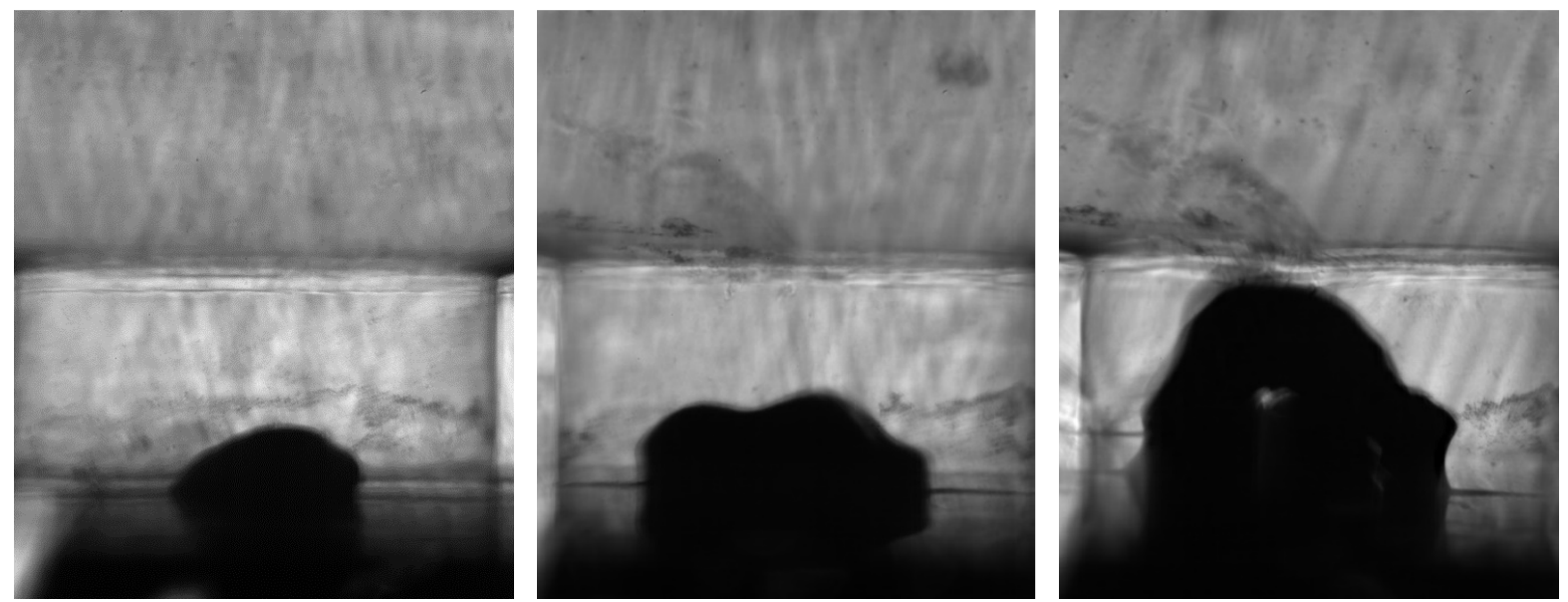

Figure 6. The exit orifice in detail. $\mathrm{SR}$ atomizer, equivalent $0.5 \mathrm{MPa}(\mathrm{Re}=1075)$, equivalent $1 \mathrm{MPa}(\mathrm{Re}=1431)$, equivalent $1.5 \mathrm{MPa}(\mathrm{Re}=1731)$

The situation changes dramatically when the SR atomizer was used. The air core is no longer present in the swirl chamber and the spray becomes unstable, even for the highest Re values. Only fragments of the core are visible inside the exit orifice - see Figure 6. The air core was unstable and strongly fluctuating and even occasionally disappeared. This behaviour was observed for all regimes studied.

It shows that our former hypothesis, as regards a periodically decaying air core as based on the external observation of the spray for the real atomizer [14], was misleading; the air core is not formed at all. The liquid, contained in the spill-line, is probably sucked back into the swirl chamber due to the low-pressure regime in the swirl chamber. That agrees with a fact that atomizers with the spill-orifice placed off-axis have a stable spray under all regimes [14].

\section{Velocity profile inside the swirl chamber}

The measured profiles of the swirl velocity (Figure 7, left) show a disparity between the Simplex and SR atomizers. The velocity profile for the Simplex version features a relatively sharp maximum near the air core interface while the SR atomizer shows a flatter peak with lower velocity maximum at similar Re values. As no air core is formed this behaviour would be expected.

\section{Numerical results}

The numerical results, when compared with the experiments in terms of global characteristics $\left(C_{D}\right.$ and $\left.S C A\right)$ and, give a very good agreement (Table 3). The most significant difference was found in the case of low Re values, but it was still less than $5 \%$.

In all the numerical simulations of the Simplex atomizers, the wavy interface between the liquid and gas phases was unsteady, see Figure 3, right. The frequency of the surface wave in the centre of the swirl chamber was, in the case of $p$-cymene, for $R e=1021$ about $25 \pm 4 \mathrm{~Hz}$, which is quite comparable to $f=32 \pm 4 \mathrm{~Hz}$ as in the experiment. The unstable behaviour of the SR atomizer was well captured by the simulation. The air core was limited to the exit orifice area in the similar way as it was in the experiments. The SCA fluctuated between 56 and 86 deg.

The swirl velocities are almost identical for all axial distances in both experiment and simulation (see Figure 7, right). This is in agreement with the inviscid theory where the swirl velocity is depended on the inlet velocity and radial distance from the axis of the swirl chamber out to the mid-point of inlet ports. The trends in the swirl velocity profiles were equivalent between experiments and simulations. The simulation slightly underestimates the velocity magnitude at the higher radius.

Similar work was done by Hansen and Madsen [21, 22] who performed both experimental and 3D computational studies of a large-scale PS atomizer. Their earlier study [21] showed that the numerical simulation significantly underestimated the swirl velocity magnitude. In their following work [22], the numerical grid was modified and the inlet tangential ports were properly modelled which reduced the differences between the experimental and numerical velocity magnitude. This is in contrast to our case where the $2 \mathrm{D}$ simulation without properly modelled inlet ports was able to predict swirl velocity closely. 
Table 3 Comparison of numerical and experimental results of real simplex atomizer

\begin{tabular}{|c|c|c|c|c|c|c|c|c|}
\hline \multirow{2}{*}{} & \multicolumn{2}{|c|}{$\mathbf{R e}=\mathbf{7 5 5}$} & \multicolumn{2}{c|}{$\mathbf{R e}=\mathbf{1 0 2 1}$} & \multicolumn{2}{c|}{$\mathbf{R e}=\mathbf{1 2 5 2}$} & \multicolumn{2}{c|}{ SR, Re=1431 } \\
\cline { 2 - 9 } & Num. & Exp. & Num. & Exp. & Num. & Exp. & Num. & Exp. \\
\hline $\boldsymbol{C}_{\boldsymbol{D}}[-]$ & 0.410 & 0.387 & 0.359 & 0.369 & 0.366 & 0.365 & 0.491 & 0.519 \\
\hline SCA $[$ deg] & 56.7 & 58.6 & 58 & 61.5 & 58.7 & 62.3 & 72 & 73 \\
\hline $\boldsymbol{d}_{\mathbf{a}} / \boldsymbol{d}_{\boldsymbol{o}}[-]$ & 0.623 & 0.698 & 0.710 & 0.708 & 0.711 & 0.712 & $\mathrm{~N} / \mathrm{A}$ & $\mathrm{N} / \mathrm{A}$ \\
\hline
\end{tabular}
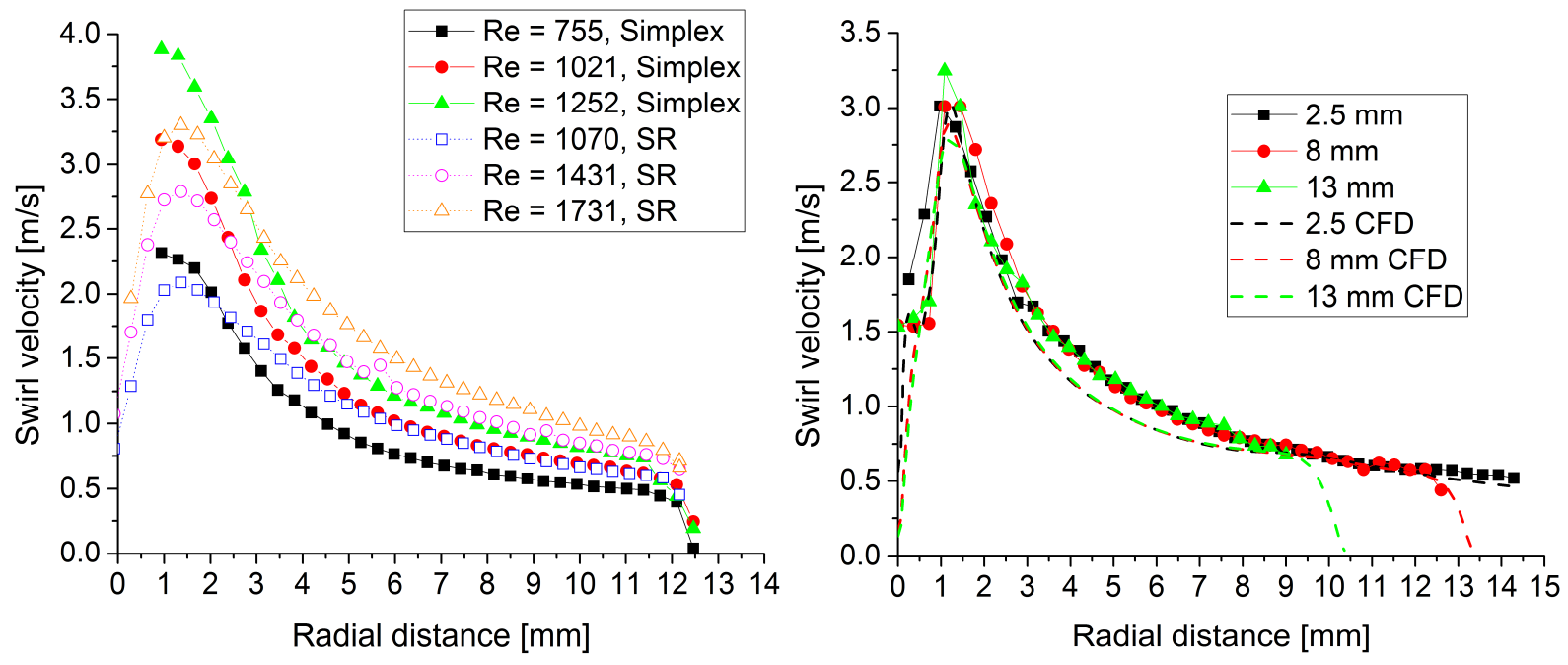

Figure 7. Swirl velocity profiles from various atomizers, left: kerosene, cross-section b (8 $\mathrm{mm}$ from the top), right: comparison of numerical and experimental profiles of swirl velocity, kerosene, simplex, $R e=1021$.

\section{Conclusions}

The internal flow characteristics of a Simplex and an SR atomizer, with a central SR orifice, were examined both experimentally and numerically. The numerical results were verified against the results obtained from the images and point wise LDA measurements.

The Simplex atomizer featured a stable, cylindrically shaped air core. Its diameter was found independent of $\mathrm{Re}$ under the measured range of operation conditions.

The numerical simulation, assuming laminar flow, was able to predict the global characteristics $\left(C_{D}, S C A\right)$ closely. The trends and magnitude in mean swirl velocity were both well captured. Unstable waves were observed on the surface of the air core using high speed imagining and were also predicted by the numerical simulation.

The SR atomizer produced an internal flow without the air core and the spray therefore fluctuated strongly. The velocity profiles showed lower and flatter peak values in comparison to the simplex atomizer at similar Re values. This study forms the groundwork for an analysis into the internal flow of SR atomizers. Further investigations including a more realistic 3D computational model, several different arrangements of the spill orifice and a range of spill to feed ratios will follow.

\section{Acknowledgements}

This work has been supported by the project No. GA15-09040S funded by the Czech Science Foundation and the project LO1202 NETME CENTRE PLUS with the financial support from the Ministry of Education, Youth and Sports of the Czech Republic under the "National Sustainability Programme I" and project Reg. No. FSI-S-17-4444 funded by the Brno University of Technology. 


\section{Nomenclature}

$\begin{array}{ll}A & \text { area [mm²] } \\ b & \text { width [mm] } \\ C_{D} & \text { discharge coefficient [-] } \\ \mathrm{d} & \text { diameter [m] } \\ f & \text { frequency [Hz] } \\ \mathrm{Fr} & \text { Froude number [-] } \\ h & \text { height [mm] } \\ \dot{m} & \text { mass flow rate }[\mathrm{kg} / \mathrm{s}] \\ Q & \text { Volumetric flow rate }\left[\mathrm{m}^{3} / \mathrm{s}\right] \\ r & \text { radial distance }[\mathrm{mm}] \\ \mathrm{Re} & \text { Reynolds number }[-] \\ \mathrm{SCA} & \text { spray cone angle [deg] }\end{array}$

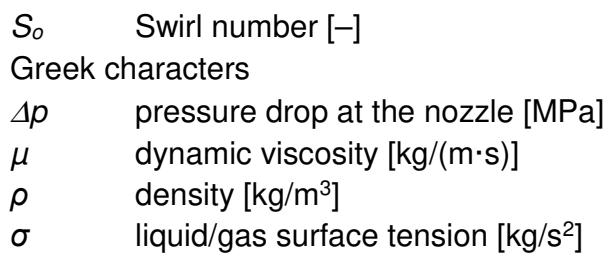

$\begin{array}{ll}\begin{array}{l}\text { Subscripts and Superscripts } \\ I\end{array} & \text { atomized liquid } \\ o & \text { exit orifice } \\ s & \text { swirl chamber } \\ p & \text { inlet port } \\ a & \text { air core }\end{array}$

\section{References}

[1] Taylor, G. I., 1948, "The Mechanics of Swirl Atomizers," International Congress of Applied MechanicsLondon. [2] Chinn, J. J., 2009, "An appraisal of swirl atomizer inviscid flow analysis, Part 1: The principle of maximum flow for a swirl atomizer and its use in the exposition and comparison of early flow analyses," Atomization and Sprays, 19(3).

[3] Chinn, J. J., 2009, "An appraisal of swirl atomizer inviscid flow analysis, part 2: inviscid spray cone angle analysis and comparison of inviscid methods with experimental results for discharge coefficient, air core radius, and spray cone angle," Atomization and Sprays, 19(3).

[4] Rizk, N. K., and Lefebvre, A. H., 1985, "Internal flow characteristics of simplex swirl atomizers," Journal of Propulsion and Power, 1(3), pp. 193-199.

[5] Jones, A., 1982, "Design optimization of a large pressure-jet atomizer for power plant," Proc. Proceedings of the Second International Conference on Liquid Atomization and Spray Systems, p. 181.

[6] Ballester, J., and Dopazo, C., 1994, "Discharge coefficient and spray angle measurements for small pressureswirl nozzles," Atomization and sprays, 4(3).

[7] Benjamin, M., Mansour, A., Samant, U., Jha, S., Liao, Y., Harris, T., and Jeng, S., "Film thickness, droplet size measurements and correlations for large pressure-swirl atomizers," Proc. ASME 1998 International Gas Turbine and Aeroengine Congress and Exhibition, American Society of Mechanical Engineers, pp. V003T006A050V003T006A050.

[8] Wimmer, E., and Brenn, G., 2013, "Viscous flow through the swirl chamber of a pressure-swirl atomizer," International Journal of Multiphase Flow.

[9] Malý, M., Janáčková, L., Jedelský, J., Jícha, M., 2016, "Impact of alternative fuel rheology on spraying process of small pressure-swirl atomizer," Proc. AIP Conference Proceedings, AIP Publishing, p. 020031.

[10] Halder, M., Dash, S., and Som, S., 2002, "Initiation of air core in a simplex nozzle and the effects of operating and geometrical parameters on its shape and size," Experimental thermal and fluid science, 26(8), pp. 871-878.

[11] Lee, E. J., Oh, S. Y., Kim, H. Y., James, S. C., and Yoon, S. S., 2010, "Measuring air core characteristics of a pressure-swirl atomizer via a transparent acrylic nozzle at various Reynolds numbers," Experimental thermal and fluid science, 34(8), pp. 1475-1483.

[12] Kim, S., Khil, T., Kim, D., and Yoon, Y., 2009, "Effect of geometric parameters on the liquid film thickness and air core formation in a swirl injector," Measurement Science and Technology, 20(1), p. 015403.

[13] Moon, S., Abo-Serie, E., and Bae, C., 2009, "Air flow and pressure inside a pressure-swirl spray and their effects on spray development," Experimental Thermal and Fluid Science, 33(2), pp. 222-231.

[14] Jedelsky, J., Malý, M., Janáčková, L., and Jícha, M., 2016 "Effect of Geometric Factors on Spray Characteristics and Stability for Small Spill-Return Pressure-Swirl Atomizers," ILASS 2016 Brighton, p. 12.

[15] Khavkin, Y., 2004, The Theory and Practice of Swirl Atomizers, Taylor \& Francis.

[16] Chinn, J. J., 2008, "The numerics of the swirl atomizer."

[17] Amini, G., 2016, "Liquid flow in a simplex swirl nozzle," International Journal of Multiphase Flow, 79, pp. 225235.

[18] Datta, A., and Som, S., 2000, "Numerical prediction of air core diameter, coefficient of discharge and spray cone angle of a swirl spray pressure nozzle," International journal of heat and fluid flow, 21(4), pp. 412-419.

[19] Moon, S., Abo-Serie, E., and Bae, C., 2010, "Liquid film thickness inside the high pressure swirl injectors: Real scale measurement and evaluation of analytical equations," Experimental Thermal and Fluid Science, 34(2), pp. 113-121.

[20] Sumer, B., Erkan, N., Uzol, O., and Tuncer, I., 2012, "Experimental and Numerical Investigation of a Pressure Swirl Atomizer."

[21] Hansen, K., Madsen, J., Trinh, C., Ibsen, C., Solberg, T., and Hjertager, B., 2002, "A computational and experimental study of the internal flow in a scaled pressure-swirl atomizer," Zaragoza, 9, p. 11.

[22] Madsen, J., Hjertager, B. H., and Solberg, T., 2004, "Numerical simulation of internal flow in a large-scale pressure-swirl atomizer," Proc. ILASS-Europe 2004, pp. 183-188. 